\title{
METAMORFOSES DO ESTADO BRASILEIRO NO FINAL DO SÉCULO XX*
}

\section{Brasilio Sallum Jr.}

O objetivo deste artigo é analisar algumas das mudanças políticas mais importantes ocorridas no Estado brasileiro nas últimas duas décadas do século XX. Para isso focalizarei dois processos que alteraram tanto o Estado como suas relações com a ordem social e a ordem econômica: a democratização política e a liberalização econômica.

Esses dois processos foram dimensões-chave da transição política que transformou a forma autocrática e desenvolvimentista de Estado, vigente

* Agradeço a Lawrence Whitehead, Maria D'Alva Kinzo e Eduardo Kugelmas pelos valiosos comentários a este artigo. Ele é uma versão alterada do texto apresentado no Seminário Fifteen Years of Democracy in Brazil organizado pelo Institute of Latin American Studies em Londres, em fevereiro de 2001.

Artigo recebido em março/2003.

Aprovado em maio/2003. no Brasil desde os anos de 1930. Ao longo de sua existência, este Estado cumpriu o papel de núcleo organizador da sociedade, deixando pouco espaço para a organização e a mobilização autônomas de grupos sociais (sobretudo dos vinculados às classes populares), e funcionou como alavanca para a construção de um capitalismo industrial, nacionalmente integrado mas dependente do capital externo, por meio de uma estratégia de substituição de importações. ${ }^{1}$ Essa forma de Estado vem sendo denominada "varguista", pois adquiriu suas características básicas sob a presidência de Getúlio Vargas. Adotarei essa denominação porque ela acentua o caráter específico do Estado, cuja superação se estudará neste artigo. Não tenho dúvidas, porém, de que ele é uma entre outras modalidades autocráticas e desenvolvimentistas de Estado ocorridas na periferia capitalista no mesmo período.

A transição política brasileira começou com a crise de Estado de 1983-1984 e terminou 
com o primeiro governo de Fernando Henrique Cardoso, momento em que o Estado ganhou estabilidade segundo um novo padrão hegemônico de dominação, moderadamente liberal em assuntos econômicos e completamente identificado com a democracia representativa. Nessa transição, a democratização política foi mais importante na década de 1980 ao passo que a liberalização econômica destacou-se nos anos de 1990. Essa transformação política só pode ser completamente entendida se a considerarmos no contexto da transnacionalização do capitalismo (desencadeada pela globalização financeira) e da democratização da sociedade brasileira.

$\mathrm{Na}$ próxima seção procuro caracterizar a crise do Estado varguista em função de sua importância para a explicação dos processos de democratização política e liberalização econômica. Essas duas dimensões serão os objetos centrais da segunda e terceira seções do artigo, respectivamente. Ao final, faço um esboço das mudanças políticas recentes que apontam para o predomínio de um desenvolvimentismo renovado e para um aprofundamento da democracia.

\section{Crise de Estado e transição política}

O cerne da crise do Estado desenvolvimentista brasileiro foi, do ângulo econômico, a incapacidade de fazer frente aos pagamentos da dívida externa no início da década de 1980, ${ }^{2}$ colocando em xeque o padrão costumeiro de relacionamento do Brasil com a ordem capitalista mundial. Dessa forma, a crise só poderia ser contornada ou superada mediante um re-arranjo da articulação que havia permitido que o país tivesse apresentado até então um desenvolvimento capitalista pujante, embora dependente. Conforme fosse o caminho escolhido para enfrentar a situação, poderiam surgir fraturas nas relações do Brasil com centros econômicos e políticos mundiais mais importantes e/ou na própria base doméstica de sustentação política do Estado.

Ademais, a situação era tanto mais difícil porque as mudanças em curso nos âmbitos internacional e doméstico acentuavam os riscos dessas fraturas. Externamente, a moratória mexicana resultou na suspensão dos fluxos voluntários de empréstimos bancários para o Brasil e outros países devedores latino-americanos de 1982 até o final da década, o que provocou uma profunda crise econômica na região. Além disso, desde meados da década de 1970, as idéias predominantes nos países centrais e nas agências financeiras multilaterais em relação à política econômica moveram-se, cada vez mais, do paradigma keynesiano para a ortodoxia monetarista, inclinada a adotar políticas rígidas de contenção de gastos públicos e de controle monetário. Essas mudanças nos fluxos econômicos e nas idéias predominantes em relação à gestão econômica restringiram muito a autonomia das políticas econômicas nacionais. ${ }^{3}$

Internamente, as mudanças políticas iniciadas nos anos de 1970 e aprofundadas desde então também dificultaram a rearticulação externa. De fato, nas eleições de 1982, o partido de sustentação do regime militar perdeu sua maioria absoluta na Câmara dos Deputados e dez governos estaduais importantes passaram a ser governados por partidos da oposição. ${ }^{4}$ Com tais resultados, o processo de liberalização política, iniciado por Ernesto Geisel em 1973-1974, pôs mais uma vez em xeque o controle do regime militar sobre a mudança política do país. ${ }^{5}$ Com efeito, esses insucessos políticos aprofundaram o padrão segundo o qual mudanças sociais empurravam sempre, para além de seus próprios limites, o projeto de liberalização política do regime militar. De fato, a partir de 1970, os alicerces politicamente excludentes do regime militar e do velho Estado varguista foram abalados por um vigoroso processo de democratização política. As classes populares tornaram-se politicamente muito mais autônomas e tentaram partilhar valores materiais e não-materiais que antes eram exclusivos das classes média e alta. Por meio das eleições, das atividades de novas associações civis ou da renovação da atuação de velhas associações, as classes populares, parte das classes médias e, até mesmo, alguns setores empresariais passaram a pôr em xeque a capacidade de o Estado controlar, como antes, a sociedade. ${ }^{6}$

Dessa forma, no início dos anos de 1980, o governo brasileiro encontrava-se em campo mina- 
do. Na escolha da estratégia para enfrentar a crise, ele sofria, ao mesmo tempo, pressões externas para conduzir o país em direção à ortodoxia econômica e estímulos na direção oposta, decorrentes das novas condições políticas internas. Embora o governo tenha optado por um ajuste externo produção de megasaldos no comércio exterior para pagar o serviço da dívida externa - acompanhado de um ajuste fiscal pouco drástico, isso foi suficiente para causar sérios danos ao seu suporte sociopolítico?

Com efeito, a estratégia escolhida para enfrentar o estrangulamento externo produziu uma crise política muito complexa. ${ }^{8}$ Ela começou por dissociar o governo da base de sustentação sociopolítica do Estado varguista. O "ajuste externo" opôs-se ao receituário econômico da coalizão desenvolvimentista, que via no crescimento econômico nacional o valor básico a ser alcançado e fazia das empresas estatais seu pilar central de sustentação. A política governamental foi considerada recessiva, inflacionária e "injusta", pois transferia todos os custos do "ajuste" para os agentes econômicos domésticos, principalmente para os assalariados e para as empresas estatais, evitando onerar os credores externos. Assim, as políticas de governo não só se dissociaram dos interesses imediatos da base de sustentação do Estado como passaram a ser consideradas ilegítimas, contrárias aos valores básicos da aliança desenvolvimentista.

Um dos resultados disso foi que parte da velha coalizão desenvolvimentista passou a se opor ao governo. As reações dos dirigentes das empresas estatais, duramente atingidas pela política de "ajuste" escolhida, foram pouco explícitas, em função mesmo do caráter autoritário do regime. Sua oposição manifestou-se indiretamente, pela resistência intra-burocrática aos comandos governamentais e pela atuação de parlamentares sintonizados com as estatais no Congresso. Os empregados das empresas estatais, pelo contrário, manifestaram-se pública e claramente contra a política do governo, seja com demonstrações de rua, seja pela greve de protesto.

Foi no empresariado privado, porém, que ocorreu a fratura mais importante da base de apoio do Estado. Parte das elites empresariais não apenas se opôs à estratégia governamental de ajuste, mas aderiu a "projetos" alternativos para enfrentar a crise econômica, indicando claramente o esvaziamento da liderança do governo. Uma porção da elite empresarial, a dissidência mais numerosa, foi magnetizada por uma versão mais nacionalista e industrialista de desenvolvimentismo e uma outra, bem menor, foi atraída por uma variante periférica de neoliberalismo.

Essas reações surgidas no interior da elite empresarial e no sistema de empresas estatais favoreceram a atuação da oposição político-partidária no Congresso e seus esforços para mobilizar as classes médias e populares na luta contra a perpetuação do regime militar. Essa mobilização de massa resultou, entre janeiro e março de 1984, na mais importante demonstração pública ocorrida no Brasil em favor da democratização política - a campanha das "Diretas Já".

A mobilização popular minou completamente o apoio ainda existente à política de democratização gradual e limitada liderada pelo regime autoritário. Com isso, a crise política expandiu-se e aprofundou-se: a perda de legitimidade do governo estendeu-se, incluindo o próprio regime autoritário. Mais ainda, naquela conjuntura crítica, foi iniciada a ruptura dos limites da legitimidade do Estado varguista. A entrada maciça da população na luta política em favor da superação rápida do regime autoritário produziu uma inovação substancial na vida política brasileira: obrigou o governo a tolerá-la, os meios de comunicação de massa fiéis ao regime a noticiála e as elites políticas a rejeitar as costumeiras condicionalidades interpostas à vigência da democracia no Brasil. De fato, a idéia de que não há democracia sem participação popular e de que não há participação popular sem a liberdade plena de associar-se e de manifestar demandas coletivas fortaleceu-se social e politicamente pelo amplo apoio das classes médias e das massas populares. A Campanha das Diretas redefiniu o espaço legítimo da política no Brasil.

Em suma, apoiada pela mobilização de massa, a oposição produziu uma crise no padrão vigente de hegemonia política. Daí em diante seria inaceitável um Estado que impusesse restrições à 
expressão e à organização políticas das massas populares; um Estado assim só poderia se manter pela força e/ou pelo interesse. Dessa forma, a campanha "Diretas Já" anunciou um novo projeto de Estado, orientado por valores democráticos surgidos do clamor da sociedade pela democratização.?

Todavia, o regime militar derrotou no Congresso Nacional a proposta de eleições diretas para a Presidência da República, minimizando com isso os efeitos políticos mais profundos da crise de hegemonia desencadeada pela mobilização de massa. O governo conseguiu, usando as alavancas de poder de que dispunha, contornar parcial e provisoriamente a crise: manteve as massas populares fora do processo imediato de escolha do novo presidente da República, mas não conseguiu evitar que boa parte de sua base político-partidária apoiasse a eleição de um governo civil liderado pela oposição. Não há dúvida, porém, quanto aos efeitos conservadores da exclusão das massas da sucessão presidencial: a oposição política, minoritária no Colégio Eleitoral, só teve condições efetivas de vencer moderando suas ambições e efetuando um pacto político com dissidentes do regime autoritário. Ademais, os programas dos candidatos permaneceram dentro dos limites dados pelo próprio governo e por empresários dissidentes. Tancredo Neves, candidato da Aliança Democrática, ${ }^{10}$ assimilou algumas das propostas desenvolvimentistas que contavam principalmente com apoio no empresariado industrial. O candidato de direita, Paulo Maluf, fez algo semelhante em relação ao projeto neoliberal, que tinha suporte de associações comerciais e no setor agrícola de exportação. Mesmo com tais limitações, as propostas anunciavam sua sintonia com as aspirações populares de implantar a democracia política no país.

A esmagadora vitória de Tancredo Neves no Colégio Eleitoral mostrou bem quais eram as aspirações políticas dominantes na elite política brasileira e, implicitamente, qual o projeto político que prevaleceria no período presidencial seguinte: construir uma Nova República, uma democracia plena, que não impusesse restrições aos movimentos e às organizações populares, que tivesse como orientação econômica um nacional-desen- volvimentismo renovado e que combinasse crescimento econômico e redistribuição de renda.

\section{A Nova República: democratização e desenvolvimentismo}

Durante o governo Sarney ${ }^{11}$ o legado institucional autoritário ajustou-se ao processo de democratização em curso, traduzindo as demandas de ampliação do espaço da política e do universo de seus participantes reconhecidos em regime político democrático. Isso implicou tanto o rompimento dos limites institucionais impostos à participação e à organização política das classes populares como a expansão dos direitos básicos do cidadão. Eliminou-se, assim, na Nova República, um dos pilares centrais do Estado varguista em qualquer de suas formas de organização política.

De fato, já no início do governo de José Sarney alterou-se um conjunto de leis que bloqueavam a participação política popular. No primeiro semestre de 1985 foram instituídos: a) eleições diretas, em dois turnos, para a Presidência da República; b) eleições diretas nas capitais dos estados, áreas de segurança e principais estâncias hidrominerais; c) representação política para o Distrito Federal na Câmara dos Deputados e no Senado Federal; d) direito de voto aos analfabetos; e) liberdade de organização partidária, mesmo para os comunistas; e todo um conjunto de alterações menores que iam na mesma direção. Além disso, a legislação sofreu algumas mudanças que provocaram um enorme impacto na atividade política dos trabalhadores, aumentando muito seus direitos de participação e liberando-os do controle governamental: a) foram readmitidos líderes sindicais, antes demitidos por "mau comportamento"; b) foi cancelado o controle do Ministério do Trabalho sobre as eleições sindicais; e c) foi eliminada a proibição de associações inter-sindicais, o que legalizou as atividades das centrais sindicais que, até então, eram apenas toleradas.

Essas e outras mudanças nas normas que regulavam a vida pública e também a tolerância governamental, quando do desrespeito à lei nas manifestações coletivas, permitem caracterizar a Nova 
República como um arranjo político no qual vários segmentos sociais, inclusive as classes populares, puderam lutar por seus interesses e idéias com grande liberdade de ação e organização. Demonstra bem este ponto o crescimento extraordinário do número de greves e dias parados durante o governo Sarney. ${ }^{12}$

O aumento da participação popular afetou a hierarquia entre os centros de poder do Estado, a gestão governamental e a amplitude dos direitos de cidadania. De fato, a crise de hegemonia enfraqueceu a hierarquia que caracterizava o regime autoritário anterior. Na Nova República as pressões da base para o topo da sociedade fortaleceram a autonomia dos centros de poder que antes costumavam ser subalternos. Portanto, o Congresso Nacional, o Judiciário, os governos dos estados e os partidos políticos ganharam mais latitude de ação em relação à Presidência da República.

As mudanças nas instituições políticas e no âmbito de poder dos diversos atores culminaram na Constituição de 1988, que ampliou o poder de ação do Legislativo, do Judiciário e do Ministério Público nos processos de decisão governamentais. Parte da base material para exercer o poder - impostos e autonomia financeira - foi transferida da União para os estados e municípios, a ponto de transformar os últimos em verdadeiras unidades federadas (não subordinados aos estados). Em relação aos direitos de cidadania, a nova Constituição estabeleceu uma regra política democrática e ampliou a proteção social para todos, trabalhadores ou não. Definiu como dever do Estado garantir vários direitos sociais - inclusive alguns direitos difusos, como os relacionados à proteção do meio ambiente - e tornou possível que cidadãos e coletividade exigissem o cumprimento dessas garantias pelo poder público. Além disso, os constituintes ampliaram drasticamente o âmbito das atividades dos promotores públicos fazendo do Ministério Público um ramo especial do Estado, independente dos três poderes clássicos. Em sua nova forma, o Ministério Público recebeu a missão de assegurar o cumprimento dos direitos da cidadania, garantidos em lei, inclusive contra a ação ou a omissão do Estado.

Ao mesmo tempo, a mesma Constituição de 1988 emprestou uma moldura legal rígida ao desen- volvimentismo democratizado: foram ampliadas as restrições ao capital estrangeiro, as empresas estatais ganharam mais espaço para suas atividades, o Estado obteve mais controle sobre o mercado e os servidores públicos e outros trabalhadores viram aumentar sua estabilidade no emprego e vários benefícios, inclusive os de aposentadoria. Portanto, a Constituição de 1988 assegurou a permanência à velha articulação entre o Estado e o mercado no momento mesmo em que o processo de transnacionalização e a ideologia liberal estavam para ganhar uma dimensão mundial em função do colapso do socialismo de Estado.

Dessa forma, durante a presidência de José Sarney, a elite política brasileira realizou completamente, do ponto de vista institucional, o projeto da Nova República. Ainda assim, esta não se converteu em um sistema estável de poder. A elite política dirigente fracassou em articular uma nova coalizão sociopolítica que sustentasse o projeto desenvolvimentista democratizado para, por esta via, superar a crise de Estado. A instabilidade econômica crescente no governo Sarney sinalizava, de fato, a fragilidade política do Estado. No entanto, não se tratava apenas de a elite política ter ou não ter as idéias certas ou de ela fazer ou não as alianças apropriadas para estabilizar um novo sistema de poder. Na verdade, as circunstâncias em que ela operava eram muito difíceis para que pudesse ter sucesso.

Com efeito, a elite política tentou renovar a estratégia desenvolvimentista, combinando distribuição e crescimento econômico, mas o fez em um contexto externo muito adverso que, em vez de ser uma fonte de capitais (empréstimos estrangeiros ou investimentos), os drenava continuamente do país (como obrigações internacionais). Ademais, a elite dirigente enfrentou esse ambiente inóspito em circunstâncias políticas muito desfavoráveis. Ela teve de lidar com uma sociedade onde os movimentos sociais e as organizações coletivas floresciam e demandavam enfaticamente a satisfação imediata de suas carências. Talvez se possa dizer que, em uma sociedade tão esperançosa como era o Brasil da Nova República, a escassez de recursos não dava muito espaço para negociações políticas bem-sucedidas. 
Ademais, a elite política tentou resolver os problemas surgidos com a crise do Estado varguista como se o Estado não tivesse perdido muito de sua autoridade política e de sua força material. Em função dessas perdas, as tentativas ortodoxas ou heterodoxas ${ }^{13}$ de enfrentar a instabilidade econômica depararam-se seja com ameaças coações externas decorrentes da ameaça ou da falta de pagamento de débitos, seja com o veto e/ou a adesão reticente de membros da velha aliança desenvolvimentista que sustentava o Estado, embora já sem articulação e objetivos definidos. Com efeito, além dos credores privados externos, governos estrangeiros e organizações multilaterais, as atividades das coletividades novas ou renovadas, inspiradas em ideário ora conservador ora reformista e constituídas a partir de distintas bases socioeconômicas, ajudaram a moldar as políticas estatais, algumas vezes estimulando e outras colocando alguns limites à ação do Estado. Organizações de empresários agrícolas e de proprietários de terra, por exemplo, restringiram o programa de reforma agrária a um mínimo e, por sua atuação junto ao Congresso Constituinte, conseguiram assegurar amplamente os direitos de posse da terra. Em sentido oposto, em 1989, ano da sucessão presidencial, fortes manifestações organizadas pela Central Única de Trabalhadores(CUT) e por sindicatos levaram o Congresso Nacional a não aprovar na íntegra $\mathrm{O}$ chamado Plano Verão visto que ele tentava estabilizar a moeda reduzindo os salários reais dos trabalhadores. Seguramente, a eficácia da atuação dos movimentos e das organizações populares e das camadas médias na Nova República podem ser explicadas, em boa parte, pela fragilidade material do Estado e pela articulação frouxa de sua base de sustentação social.

Em síntese, a Nova República tornou-se um sistema instável de dominação política, em que não se articulavam bem a dimensão institucional, a esfera sociopolítica e as condições econômicas.

Essa instabilidade resultou, de um ponto de vista material, numa trajetória decadente de desenvolvimento. O Estado continuou a proteger o mercado interno, mas o dinamismo econômico anterior, que tinha permitido ao Brasil ter uma das maiores taxas de crescimento econômico do mun- do, se esvaiu. As taxas de investimento caíram drasticamente: estancou a entrada de capital estrangeiro e o Estado perdeu sua capacidade de investir. O sistema de empresas estatais, que tinham sido a vanguarda do modelo desenvolvimentista anterior, perdeu seu dinamismo próprio passando a se subordinar aos objetivos governamentais do "ajustamento", que visava a produzir insumos de preços baixos para combater a inflação e/ou ajudar o setor privado a produzir saldos crescentes no comércio exterior. A desorganização tanto da economia como das finanças públicas geraram flutuações súbitas no crescimento do PIB, uma redução do crescimento econômico médio além de intensas pressões inflacionárias. A inflação substituiu o desenvolvimento como questão política básica daquele período. Tudo isso constituiu um poderoso obstáculo para que na Nova República o processo de democratização política produzisse o seu equivalente material. Assim, embora tenha havido expansão dos serviços públicos de bem-estar, na década de 1980 os brasileiros mais pobres não aumentaram sua participação na renda nacional.

Ademais, as dificuldades de estabilizar uma nova forma de Estado estimularam o crescimento no interior da elite brasileira de um novo projeto político para o país. Com efeito, na medida em que a elite econômica se tornava insegura e assustada com as iniciativas reformistas do governo da Nova República, sobretudo com as políticas heterodoxas de estabilização monetária, as idéias econômicas liberais passaram a se tornar relevantes para ela. Além de se mostrarem ineficientes para restringir a inflação e retomar o crescimento econômico de forma sustentada, as políticas heterodoxas foram interpretadas como ameaças à propriedade privada, pois restringiam a liberdade de mercado e ameaçavam os contratos. Daí em diante, a elite empresarial mobilizou-se para moldar as estruturas e controlar as ações do Estado orientando-se, pelo menos parcialmente, pelas concepções neoliberais que vinham sendo difundidas, desde os anos de 1970, pelas instituições econômicas multilaterais, por think tanks e governos dos países centrais. ${ }^{14}$ Dessa maneira, sobretudo de 19871988 em diante, a elite econômica passou a confrontar o intervencionismo do Estado, exigin- 
do desregulamentação, melhor acolhida para o capital estrangeiro, privatização das empresas estatais etc. Assim, embora o liberalismo econômico no Brasil só tenha se tornado politicamente hegemônico nos anos de 1990, essa hegemonia começou a ser socialmente construída ainda na segunda metade da década de 1980.

Entretanto, mesmo que a retórica liberal tenha sido absorvida pelos meios de comunicação e tenha se difundido entre as camadas médias da população, isso ocorreu em menor proporção na elite política, entre os trabalhadores organizados e servidores públicos, que continuaram a defender os ideais de "propriedade nacional" e "regulação estatal".

Eis porque a Constituição de 1988, que materializou o projeto político da Nova República democratização política e desenvolvimentismo democratizado - tornou-se um alvo para os ataques da elite empresarial e de seus líderes políticos e intelectuais e, inversamente, converteu-se em trincheira para as organizações de trabalhadores, servidores, funcionários das companhias estatais e da classe média assalariada ligada ao serviço público.

A eleição direta para presidente da República em 1989 sumariou os resultados políticos do período anterior. Depois de quase trinta anos de interrupção de disputas diretas para a Presidência, a eleição foi realizada com total liberdade de expressão e reunião, constituindo um dos pontos mais altos de participação das classes populares e das camadas médias na política brasileira. Certamente, foi a crescente presença das classes populares e média na esfera pública que abriu caminho para o desempenho eleitoral dos candidatos da esquerda no primeiro turno da eleição presidencial e, especialmente, para o ex-operário metalúrgico e líder sindical Luiz Inácio da Silva (Lula) no segundo turno. Mesmo sendo candidato de um partido tão pequeno como o Partido dos Trabalhadores (PT), Lula foi derrotado apenas por uma pequena margem de votos. ${ }^{15}$ Sublinhe-se, ainda, que este ótimo resultado foi obtido sem mascarar as intenções reformistas do PT. Lula prometeu durante sua campanha uma ruptura efetiva do padrão autocrático de dominação social: as classes populares seriam conduzidas ao poder, o governo faria uma redistribuição de renda deslocando recursos do topo para a base da sociedade, realizaria uma "verdadeira" reforma agrária e as empresas estatais seriam preservadas, embora sua administração devesse ser democratizada. Em suma, o reformismo de esquerda visava a eliminar, pelo menos em parte, a "exclusão social", radicalizando o processo de democratização ao lhe dar bases materiais adequadas. No pólo oposto, dando menos de $5 \%$ dos votos aos candidatos do PMDB e do PFL o eleitorado ratificou o fracasso da elite política em converter a Nova República numa forma estável de domínio político.

O processo eleitoral foi um momento de inflexão nas referências ideológicas que polarizavam o sistema partidário. A partir da campanha de 1989, o confronto entre democracia e autoritarismo, que caracterizava o sistema partidário desde a liberalização política do regime militar, tornou-se menos relevante. As forças partidárias reorganizaram-se de acordo com novas polarizações, e, nesse processo, sobretudo as relações Estado/mercado ganharam espaço. Os partidos foram magnetizados pelas idéias econômicas liberais, de um lado, e pelo desenvolvimentismo democratizado, de outro. O Partido da Social Democracia Brasileira (PSDB), dissidência do PMDB organizada como partido em 1988, inclinou-se decisivamente para o liberalismo, como enfatizou seu candidato Mário Covas ao exigir para o país um "choque de capitalismo". O Partido Democrata Cristão (PDC) e o Partido Liberal (PL) também adotaram um programa liberal. O PDS, partido do extinto regime militar, já havia se adaptado às idéias do livre mercado desde a crise de 1983/ 84, embora elas tenham sido sufocadas na disputa eleitoral, tal como na sucessão presidencial anterior, pelo populismo conservador de seu candidato Paulo Maluf. E, apesar da retórica nacional-desenvolvimentista do candidato do PFL, Aureliano Chaves, o partido vinha apresentando, desde a Constituinte, uma crescente inflexão liberal e não the deu apoio significativo. $\mathrm{Na}$ direção contrária, o PMDB, o PDT e o PT radicalizaram o desenvolvimentismo em sua versão nacionalista e distributivista.

A campanha eleitoral de 1989 mostrou também outra polarização ideológica: a oposição en- 
tre dois tipos diferentes de ideais democráticos. Embora todos os partidos fossem favoráveis à democracia, aqueles que tinham a liberalização econômica no centro de sua agenda sinalizavam a aceitação da democracia representativa, mesmo quando questionavam a forma presidencialista de governo. No outro pólo, o da esquerda, enfatizava-se o caráter limitado da democracia representativa (o de só dar espaço para atuação popular nos períodos eleitorais) e predominava a idéia de avançar em direção a formas mais participativas de democracia.

Em suma, com a vitória de Fernando Collor de Mello - político identificado com o neoliberalismo e pouco simpático aos experimentos participativos da democracia -, as eleições presidenciais de 1989 tornaram-se o marco divisório entre dois momentos da transição política brasileira, quais sejam, o período em que predominou a democratização política e o que teve como seu impulso básico a liberalização econômica.

\section{A nova hegemonia liberal e suas conseqüências $^{16}$}

O governo Collor confirmou, em parte, a inflexão liberal manifestada no embate eleitoral de 1989. Contribuiu para danificar o quadro institucional nacional-desenvolvimentista e redirecionar a sociedade brasileira em um sentido anti-estatal e internacionalizante.

Ainda assim, embora dando ao Estado o impulso inicial para conformar uma nova estratégia de desenvolvimento, o governo Collor não conseguiu vencer a crise de Estado experimentada pela sociedade brasileira desde o início da década de 1980.

Durante o período Collor, as licenças e as barreiras não tarifárias à importação foram suspensas e as tarifárias alfandegárias foram redefinidas, criando-se um programa para sua redução progressiva ao longo de quatro anos. ${ }^{17}$ Ao mesmo tempo, programou-se a desregulamentação das atividades econômicas e a privatização das companhias estatais que não estivessem protegidas pela Constituição, afim de recuperar as finanças públicas e reduzir aos poucos o papel do Estado no incentivo à indústria doméstica. Finalmente, deu-se seqüência à política de integração regional com os países da fronteira sul, instituindo-se o Mercosul (1991), com vistas a ampliar o mercado para os produtos domésticos de seus participantes.

Essas medidas significavam o descarte da estratégia anterior de desenvolvimento, vigente plenamente até o início dos anos de 1980, cuja pretensão era construir uma estrutura industrial completa e integrada, usando o Estado como escudo protetor ante a competição externa e como alavanca do desenvolvimento industrial e da empresa privada nacional.

Essa reorientação estratégica, embora sintonizada com as novas inclinações liberais dos empresariado local e com as tendências ideológicas dominantes no plano internacional, foi insuficiente para soldar um novo pacto político que superasse a crise de hegemonia iniciada em 1983. Não obstante Collor parecesse ser um César auspicioso surgido das fissuras da ordem política em crise com a promessa de superá-la, seu governo, em vez disso, contribuiu para aprofundá-las drasticamente, frustrando as expectativas das forças políticas em cena. Para estabilizar a moeda o Plano Collor congelou preços, confiscou provisoriamente e reduziu parte da riqueza financeira das classes médias e empresariais. Assim, além de atingir a riqueza material, ameaçou a segurança jurídica da propriedade privada. Ademais, o governo submeteu as organizações tradicionais dos empresários a ataques verbais sistemáticos organizando, ao mesmo tempo, grupos de empresários para apoiá-lo na implementação de suas políticas. Também procurou exercer o poder dissociado da classe política e de seus mecanismos tradicionais de sobrevivência; reduziu as despesas do Estado de forma arbitrária por meio da demissão em massa de servidores, desorganizando a administração pública; e tentou enfraquecer as organizações oposicionistas de trabalhadores estimulando organizações alternativas ligadas ao governo. No campo internacional, Collor também teve dificuldades. Apesar de sua orientação liberal e internacionalizante, a primeira equipe econômica do governo tentou postergar o fim da moratória herdada do período Sarney e enfraquecer a posição dos bancos estrangeiros privados na negociação da 
dívida externa. Essa estratégia contribuiu para enfraquecer ainda mais o suporte da elite econômica brasileira e estimulou o governo dos Estados Unidos a opor-se a ele e a proteger o sistema bancário norte-americano. As dificuldades externas só diminuíram quando uma equipe econômica muito mais liberal tomou posse, em 1991. ${ }^{18}$

Nesse contexto político tão perturbado é que Fernando Collor foi acusado de ser o chefe oculto de um esquema governamental de corrupção. Depois de ser investigado e processado pelo Congresso, renunciou à Presidência da República para evitar o impeachment. ${ }^{19}$ Em suma, Collor fracassou como César. ${ }^{20}$ Suas ações acirraram a crise política. Em vez de dar às forças políticas em disputa os meios para resolver de forma negociada seus próprios impasses, ele tentou impor-lhes uma solução alternativa "de cima para baixo". Tentou restaurar de forma autocrática a estabilidade da moeda - base das relações de troca e da autoridade do Estado sobre o mercado - em uma sociedade que, embora mal alinhavada politicamente, já havia avançado muito no caminho da democratização. Com efeito, o impeachment do presidente Collor de Mello dificilmente teria ocorrido se não houvesse avançado tanto na sociedade o sentimento/concepção de que o governo e o Estado deviam obedecer a limites políticos e morais muito mais estreitos do que anteriormente. Ele também não teria ocorrido se a capacidade de ação autônoma dos vários agrupamentos sociais e dos vários centros de poder do Estado não tivesse crescido tanto. As manifestações de dezenas de milhares de jovens "caras pintadas" que exigiram nas ruas o impeachment, os testemunhos corajosos de trabalhadores subalternos contra o chefe de Estado, a conduta autônoma da imprensa, do rádio e da televisão, assim como do Congresso e do Judiciário são expressões - cada uma a seu modo - do processo de democratização política do país.

Embora este governo tenha fracassado na tentativa de superar a crise brasileira, desde o final dos anos de 1980 as condições econômicas internacionais vinham se tornando mais positivas para os países da periferia. Alguns fatores e decisões políticas possibilitaram essa reversão, como o gran- de aumento no volume das aplicações financeiras nos países centrais e em direção aos mercados "emergentes", o "alívio" produzido nas carteiras dos credores em função do Plano Brady de renegociação da dívida externa e o aperfeiçoamento das políticas de liberalização econômica nos países periféricos. ${ }^{21}$ De qualquer forma, "depois de quase dez anos de transferências de recursos líquidos negativos, a América Latina recebeu transferências positivas do resto do mundo. A magnitude dos fluxos de capital líquido para a nação cresceu drasticamente em 1992 e 1993, ultrapassando 20 bilhões de dólares" (Edwards, 1995, p. 82).

O grande afluxo de capital para o Brasil,$^{22}$ os legados do período Collor (avanço do liberalismo econômico, no plano ideológico e institucional, e rejeição a soluções autocráticas para a crise), a exacerbação da instabilidade político-econômica durante o período Itamar Franco e o avassalador crescimento do prestígio popular de Luiz Inácio da Silva, candidato de esquerda à Presidência de República, foram algumas das condições e, ao mesmo tempo, alavancas poderosas para a nova tentativa, realizada em 1994, de superar a crise de hegemonia que minava a sociedade brasileira desde o início da década de $1980 .{ }^{23}$

As condições e as características do sistema institucional brasileiro especificam a fortuna com que se defrontaram algumas lideranças políticas que, bem situadas no seio do Estado e temerosas de perder o seu controle, tiveram virtú suficiente para aproveitar a ocasião e negociar a associação entre partidos de centro e de direita em torno da continuidade das reformas liberais, da estabilização da economia e da tomada do poder político central. Tudo isso foi materializado nos lançamentos bem-sucedidos do Plano Real e da candidatura à Presidência da República de seu articulador, o então Ministro da Fazenda, Fernando Henrique Cardoso.

A referência à fortuna e à virtú permite retomar cum grano salis a idéia de "momento maquiaveliano", de John Poccok, que enfatiza o papel da liderança na manipulação criativa das oportunidades legadas pela fortuna para fazer prevalecer os interesses gerais da comunidade política ameaçada pela confrontação entre interesses particularistas, reconstruindo com isso o Estado. ${ }^{24}$ 
Segundo Sola e Kugelmas (1996), o próprio Plano Real teria sido a construção desse "princípio de universalidade [...] capaz de assegurar a superação da particularidade e da contingência inerentes ao comportamento descontrolado das forças em conflito", para retomar os termos segundo os quais Malloy e Connaghan (1996) definem o momento maquiaveliano. Seguindo esse raciocínio, a utilização criativa da Revisão Constitucional ${ }^{25}$ em curso no sentido de gerar condições fiscais mínimas para a estabilização (Fundo Social de Emergência, votado em fevereiro de 1994); a instituição de uma moeda paralela, a URV (Unidade de Referência Variável), unidade de conta que generalizou a indexação e sincronizou preços e salários, criando uma espécie de "hiperinflação de laboratório"; e a substituição, no dia $1^{\circ}$ de julho de 1994, da URV pelo real, nova moeda ancorada, mas não igual, ao dólar; tudo isso, além de dezenas de regulamentações específicas, teria produzido a estabilidade.

Contudo, o Plano Real não foi senão um passo, certamente essencial, na construção do "princípio de universalidade" que permitiu superar a conjuntura crítica anterior. Embora tenha sido uma fórmula técnica brilhante para estabilizar a moeda, cujo sucesso foi essencial também do ponto de vista eleitoral, o Plano foi apenas uma peça subordinada do "momento maquiaveliano", cujo elo principal foi a aliança política entre partidos de centro e direita em torno de um projeto de tomada de poder e de reconstrução do Estado em uma perspectiva liberal. O próprio papel da liderança, sua virtú, embora crucial foi limitado, na medida em que deu o acabamento final a um processo de construção da hegemonia liberal cujos alicerces tinham sido erguidos, no plano societário, durante a segunda metade da década de 1980.

O extraordinário sucesso do Plano Real, a eleição de Fernando Henrique Cardoso para a Presidência da República já no primeiro turno, a escolha de um Congresso Nacional onde o chefe de Estado pode construir uma aliança partidária amplamente majoritária, a vitória de políticos aliados do presidente em quase todos os estados - tudo isso já permitia antever que no dia $1^{\circ}$ de janeiro de 1995 os representantes de um novo sistema hegemônico de poder assumiriam o comando de um Estado ancorado numa moeda provavelmente estável. Nada parecia faltar para que eles pudessem completar bem a tarefa de moldar a sociedade ao ideário econômico liberal.

A partir de 1995, os novos governantes trataram de eliminar os resíduos do Estado varguista e de construir novas formas de regulamentar o mercado, seguindo um sistema multifacetado de idéias, cujo denominador comum era um liberalismo econômico moderado. As características centrais desse ideário podem ser assim resumidas: o Estado deveria transferir quase todas as suas funções empresariais para a iniciativa privada; teria que expandir suas funções reguladoras e suas políticas sociais; as finanças públicas deveriam ser equilibradas e os incentivos diretos às companhias privadas seriam modestos; haveria também restrição aos privilégios existentes entre os servidores públicos; e o país deveria intensificar sua articulação com a economia mundial, embora dando prioridade ao Mercosul e às relações com os demais países sul-americanos.

Esse conjunto básico de idéias liberais materializou-se em iniciativas que mudaram drasticamente as relações anteriores entre mercado/Estado e a ordem de prioridades do Estado em relação aos segmentos socioeconômicos, tanto em termos patrimoniais como institucionais. $\mathrm{O}$ alvo central dessas políticas era solapar alguns dos fundamentos legais do Estado nacional-desenvolvimentista, em parte assegurados pela Constituição de 1988, e diminuir a participação do Estado nas atividades econômicas. Neste ponto, o governo de Cardoso foi bem-sucedido, já que os projetos de reforma constitucional e infra-constitucional submetidos ao Congresso foram quase todos aprovados, entre os quais se destacaram a) o fim da discriminação constitucional ao capital estrangeiro; b) a exploração, o refino e o transporte de petróleo e gás, monopolizados pela companhia estatal de petróleo (Petrobrás), foram transferidos para a União e convertidos em concessão do Estado às empresas, principalmente a estatal, que manteve grandes vantagens em relação a outras concessionárias privadas; e c) o Estado foi autorizado a conceder 
os direitos de exploração dos serviços de telecomunicação (telefonia fixa e celular, exploração de satélites etc.) a companhias privadas (anteriormente as empresas públicas tinham o monopólio dos serviços).

Além de promover esse conjunto de reformas constitucionais, o governo Fernando Henrique Cardoso não só estimulou o Congresso a aprovar a lei complementar que regulava as concessões de serviços públicos à iniciativa privada, autorizada pela Constituição (eletricidade, estradas, ferrovias etc.), mas também conseguiu a aprovação de uma lei de proteção aos direitos de propriedade industrial e intelectual, tal como recomendado pela OMC e, ainda, efetuou um enorme programa de privatizações e venda de concessões, preservando o programa de abertura comercial já implementado. De forma similar, os governos dos estados realizaram programas de privatização e concessões, mas em menor escala.

Outra área importante atingida por medidas disciplinares foram as finanças públicas. Fixaramse limites máximos para todos os pagamentos de pessoal, as dívidas dos estados e municípios foram renegociadas e foram proibidos, por muito tempo, novos empréstimos e renegociações junto ao governo Federal. ${ }^{26}$

Esse conjunto de iniciativas parecia ter materializado o código comum de um novo bloco hegemônico de dominação, adotado por políticos e burocratas com comando sobre o poder Executivo, pela grande maioria de parlamentares, por empresários dos mais variados setores, pela mídia etc. e, gradualmente, dominou a classe média e parte do sindicalismo urbano e das massas populares. Com efeito, as medidas legislativas foram facilmente aprovadas pelo Congresso Nacional, apesar da oposição de uma minoria da esquerda portadora das bandeiras da "defesa do patrimônio público" e da "economia nacional". As privatizações e as vendas de concessões também foram bem-sucedidas e tiveram apoio popular, apesar das disputas forenses e das manifestações de rua promovidas por organizações de esquerda.

Contudo, nesse novo bloco político hegemônico, vinculado pelo já mencionado liberalismo econômico moderado, fortes divisões internas ge- raram conflitos reiterados sobre a política econômica e acabaram dando um caráter híbrido às ações do Estado. No se interior havia, de um lado, uma corrente liberal fundamentalista orientada basicamente para a estabilização monetária e comprometida com a promoção de uma economia de livre mercado e, de outro, uma tendência liberaldesenvolvimentista, mais inclinada a equilibrar estabilização monetária com um crescimento competitivo da economia local mediante a intervenção moderada do Estado.

Ao longo do primeiro mandato de Fernando Henrique Cardoso, a primeira versão de liberalismo predominou, servindo de orientação e dando consistência à ação dos que dirigiram a política econômica governamental. ${ }^{27}$ Os fundamentalistas tentaram obter a estabilização monetária com políticas de câmbio sobrevalorizado ${ }^{28}$ juros altos e ajuste fiscal brando. A segunda corrente liberal, a desenvolvimentista, não tinha a consistência da primeira, pois não possuía um texto programático nem orientava sistematicamente a ação governamental. ${ }^{29}$ Entretanto, o liberal-desenvolvimentismo inspirou algumas políticas destinadas a contrabalançar as conseqüências negativas da ortodoxia liberal para setores específicos da economia ou mesmo promover o crescimento de algumas atividades produtivas no país. Deve-se salientar que esse tipo de desenvolvimentismo liberal, em lugar de visar à construção de um sistema industrial nacionalmente integrado, reivindica que a produção doméstica tenha uma participação significativa no sistema econômico mundial. Ele só aceita formas bem definidas de intervenção estatal no sistema produtivo, como políticas industriais setoriais, desde que limitadas no tempo e no montante de subsídios. Não deseja substituir importações a qualquer custo, mas aumentar a competitividade de alguns setores econômicos e, no máximo, reduzir a dependência externa pelo "adensamento das cadeias produtivas", introduzindo novos elos no tecido industrial, sem perder de vista, porém, a necessidade de equiparar sua competitividade aos padrões internacionais. ${ }^{30}$

Embora durante o primeiro governo Cardoso a sobrevalorização do câmbio e as altas taxas de juros tenham produzido estabilidade monetária, tam- 
bém conduziram a economia brasileira a um desequilíbrio externo bastante sério. Para reduzi-lo o governo limitou um pouco a apreciação cambial e acentuou a elevação dos juros com dois objetivos complementares: refrear a atividade econômica doméstica e as importações, diminuindo em conseqüência o déficit comercial, e atrair capitais do Exterior para financiar o desequilíbrio externo do país, mantendo assim um nível de reservas alto o bastante para ancorar a nova moeda nacional. Esse programa de estabilização sustentava-se numa percepção otimista do mercado financeiro global, que via sua liquidez como permanente e capaz de equilibrar com empréstimos e investimentos desequilîbrios ocasionais no balanço de transações correntes do Brasil com o Exterior, caso o desempenho econômico do país fosse adequado.

A crise financeira do México, em dezembro de 1994, mostrou pela primeira vez os riscos de adequar a política macroeconômica à orientação liberal fundamentalista. De fato, tal crise deixou claro que, dependendo das circunstâncias internacionais, poderia ser difícil obter capital no Exterior para financiar um desequilíbrio acentuado nos balanços comerciais e de serviços. Apesar dessa advertência e embora o governo tenha adotado algumas políticas compensatórias para proteger a economia doméstica, sua orientação macroeconômica básica foi mantida até a crise cambial de janeiro de 1999.

Essa obstinação contribuiu para aumentar muito a fragilidade financeira externa da economia brasileira e a debilidade do Estado ante os credores privados, pois levou ao endividamento crescente para cobrir os desequilíbrios gerados pela política macroeconômica. Como resultado da dependência financeira, as mudanças nas condições do mercado internacional afetaram cada vez mais, pela variação do fluxo de capitais, o equilíbrio das contas externas do país e expuseram a moeda nacional a ataques especulativos tendentes a desvalorizá-la. Assim, depois da crise mexicana, a crise financeira asiática de 1997 e a moratória russa de agosto de 1998 abriram caminho a tais ataques especulativos.

Em todas essas situações críticas o país perdeu uma grande quantidade de reservas interna- cionais e o governo agiu de forma semelhante, ou seja, manteve a estabilidade da moeda elevando drasticamente os juros para preservar as reservas e refrear tanto a atividade econômica interna como o desequilibrio externo. Essas medidas conseguiram preservar o valor da moeda em relação ao dólar e manter a inflação em nível muito baixo, embora não reduzissem a fragilidade financeira externa do país, pois aumentavam a dívida pública e não reduziam o déficit de transações correntes com o Exterior. Além disso, elas restringiram muito o crescimento do produto nacional bruto e elevaram bastante as taxas de desemprego. ${ }^{31}$

A fragilidade financeira do país em relação ao Exterior acabou cobrando um preço alto demais. A política cambial brasileira teve de ser alterada no início do segundo mandato de FHC para evitar o esgotamento das reservas em moeda estrangeira que ancoravam o real. Sublinhe-se ainda que a mudança ocorreu apesar de o governo ter assinado acordo com o FMI em novembro de 1998 e ter obtido grande empréstimo dos Estados Unidos para se defender com mais segurança da fuga de capitais externos.

A substituição do antigo nacional-desenvolvimentismo por uma estratégia liberal de desenvolvimento redirecionou o Estado em relação a vários setores socioeconômicos. Ressalte-se a propósito que, desde o lançamento do Plano Real até janeiro de 1999, a estratégia liberalizante privilegiou nitidamente a esfera financeira ante as atividades produtivas e comerciais por meio das políticas de juros altos e câmbio sobrevalorizado. Estas duas políticas funcionaram o tempo todo como bombas de sucção dos recursos do Estado e das atividades produtivas e comerciais para os detentores, locais ou estrangeiros, de capital financeiro. Isso mostra haver nítida afinidade entre o predomínio do fundamentalismo liberal no bloco político hegemônico e a fase da "financeirização da riqueza" que caracteriza o capitalismo mundial contemporâneo. ${ }^{32}$

Entretanto, a transformação mais distintiva ocorrida na relação Estado/economia foi terem as empresas estatais deixado de ser os suportes da gestão econômica governamental. Além de a maioria das estatais ter sido privatizada, algumas áreas 
antes atendidas pela administração direta do Estado passaram aos cuidados de empresas privadas (manutenção de estradas de rodagem, por exemplo). A diminuição drástica das funções empresariais do Estado não eliminou o intervencionismo estatal, mas o modificou profundamente. O Estado expandiu suas funções normativas e de controle por meio de agências reguladoras setoriais (telecomunicações, eletricidade, petróleo e gás, por exemplo) e manteve grande parte de sua capacidade de moldar a atividade econômica pelo financiamento de longo prazo às empresas privadas e pela compra de bens e serviços.

Também as companhias privadas nacionais deixaram de ser o foco privilegiado das políticas estatais. Não só as companhias estrangeiras foram constitucionalmente equiparadas às nacionais, mas também a orientação estatal básica foi a de atrair ao máximo os investimentos externos e a de promover sua associação com as empresas locais. ${ }^{33}$ Além dessa orientação geral (tanto da União quanto dos estados), o governo federal tentou atrair, sistematicamente, as companhias multinacionais para ramos da indústria como o automotivo, o de telecomunicações etc., modulando as leis tributárias e o sistema de financiamento e tomando iniciativas para "vender" a imagem do Brasil como um excelente destino para o capital estrangeiro. É possível que isso tenha ajudado o Brasil a se tornar um dos maiores destinos do investimento estrangeiro direto no mundo, embora sempre ultrapassado, entre os países "emergentes", pela China. ${ }^{34}$

Outra mudança importante introduzida na relação Estado/economia é que, desde 1995, tendeu a desaparecer a prioridade política antes concedida ao desenvolvimento das manufaturas industriais. No âmbito de BNDES, principal agente financeiro da industrialização brasileira, foi notável a diversificação das atividades econômicas atendidas. Além de manufaturas, foram financiadas empresas comerciais, agrícolas etc. A agricultura empresarial, sobretudo, foi diretamente beneficiada pelo governo federal e teve seus interesses de expansão convertidos em demanda prioritária da política externa brasileira. Desde 1996 - quando ganharam impulso as discussões em torno da assinatura de acordos de livre-comércio com os Estados Unidos e a União Européia os assuntos agrícolas e a luta contra as políticas protecionistas dos países centrais tornaram-se um ponto central da diplomacia brasileira.

As mudanças na orientação do Estado foram tão profundas que romperam um dos parâmetros básicos da velha aliança nacional-desenvolvimentista: a propriedade agrária deixou de ser intocável. A própria estabilização monetária reduziu os preços da propriedade territorial, antes muito usada como reserva de valor. Além disso, não só por iniciativa do próprio governo, mas também por pressão social do Movimento dos Trabalhadores sem Terra (MST), da Confederação Nacional dos Trabalhadores Agrícolas (Contag) e da Igreja Católica, durante os dois mandatos de Cardoso desenvolveu-se um grande programa de reforma agrária. Este incluiu desapropriações de propriedades improdutivas e o assentamento de centenas de milhares de famílias de trabalhadores agrícolas sem terra, assim como um conjunto de reformas institucionais e medidas específicas que elevaram a taxação sobre terras improdutivas e aumentaram o controle do poder público sobre a propriedade fundiária, inclusive pela retomada da posse sobre imensas áreas ilegalmente apropriadas por grileiros.

\section{Liberalismo, desenvolvimentismo e democracia}

Embora a reeleição de Fernando Henrique Cardoso em 1998 e a manutenção quase total de seu suporte político (no Congresso e entre os governadores) tenham confirmado a aquiescência da maioria em relação ao programa liberal, o governo perdeu sua força política anterior, pois deixou de ter controle sobre sua política econômica (foi levado a desvalorizar da moeda em janeiro de 1999 mesmo depois de recorrer ao apoio do FMI e do governo norte-americano) e foi constrangido por enormes dificuldades econômicas.

É verdade que o governo teve sucesso na substituição do regime de câmbio semi-fixo e sobrevalorizado pelo câmbio flutuante e no manejo 
da política monetária. A estabilidade da moeda foi mantida e, depois da estagnação de 1999, houve um crescimento de $4 \%$ do PIB em 2000. Entretanto, o apoio do FMI foi dado e renovado em troca do compromisso de o governo fazer um severo ajuste fiscal, objetivando produzir um grande superávit anual nas contas públicas (sem considerar os juros devidos), um superávit grande o bastante para permitir reduzir a proporção da dívida pública em relação ao PIB..$^{35}$ Além disso, a estagnação internacional de 2001 e 2002, a crise da Argentina e o risco político associado à eleição presidencial de 2002 produziram constrangimentos adicionais às políticas governamentais. Houve, de fato, uma importante redução dos fluxos de investimentos externos diretos (IDE) para o Brasil e dificuldades para rolar as dívidas externa e interna. ${ }^{36}$

Assim, uma vez mais, revelaram-se a dependência externa e a fragilidade econômica do Brasil, apesar da nova política de câmbio flutuante. Esta não pode proteger plenamente a economia da conjuntura internacional negativa e das incertezas políticas em função das enormes dívidas externa e interna produzidas pela política de estabilização do primeiro governo Cardoso e do crônico déficit brasileiro nas suas transações correntes com o exterior. As contramedidas do Banco Central - aprofundar o ajuste fiscal, aumentar as taxas de juros e assinar novos acordos com o FMI -, embora protegessem a solvência financeira do Brasil, reduziram o crescimento do PIB em 2001 e 2002 a menos de $2 \%$ anuais. ${ }^{37}$

A nova gestão macroeconômica surgida a partir da crise cambial de janeiro de 1999 implicou algumas mudanças nas relações Estado/setores econômicos. As atividades não financeiras tenderam a ganhar mais relevância e o governo estimulou de diferentes maneiras os segmentos econômicos que podiam ajudar a produzir superávit no comércio exterior. Durante do segundo governo Cardoso até foi dada atenção e alguma ajuda às companhias que tinham certa probabilidade de competir internacionalmente como multinacionais.

Essas mudanças podem ser vistas como sinais de transformação política dentro do bloco hegemônico. Este se inclinou de forma irregular e hesitante em direção a seu pólo liberal-desenvol- vimentista. Com efeito, desde o começo de 2000 o Ministério do Desenvolvimento, o da Ciência e Tecnologia, a Secretaria do Planejamento e até a Presidência da República manifestaram sinais desse tipo de transformação, mais acentuada ainda com a aproximação das eleições de 2002. Mesmo assim, os portadores do fundamentalismo liberal mantiveram o controle sobre as principais alavancas do poder - o Ministério da Fazenda e o Banco Central - e por meio delas preservaram a prioridade para a estabilização, embora tenham adotado a política fiscal, em lugar da política cambial, como instrumento central para conservá-la. Em suma, o bloco hegemônico manteve suas divisões internas, embora atenuadas, e seus conflitos internos foram deslocados da questão cambial para assuntos fiscais. Como conseqüência, as decisões governamentais tenderam a ser lentas e não sistemáticas.

As dificuldades econômicas e políticas mencionadas contribuíram também para enfraquecer a coalizão política que governava o Estado durante o segundo governo Cardoso. No seu primeiro mandato, o presidente FHC tinha um alto prestígio popular, originado principalmente da súbita estabilização monetária, o que reforçou os poderes presidenciais usuais e o ajudou muito a lidar com a ampla coalizão de partidos governistas para executar o programa reformista liberal. Além disso, a estabilidade monetária conseguida pelo Plano Real e a política de contenção econômica que predominou no primeiro governo de Fernando Henrique Cardoso restringiu a ação dos movimentos e das organizações das massas populares. A hegemonia liberal também dificultou a mobilização dos sindicatos que se mantiveram ideologicamente vinculados a idéias estatistas ou social-democratas. Ademais, a propagação do apoio popular ao governo facilitou a adoção de um estilo tecnocrático de exercer o poder e reforçou as dificuldades de participação política popular fora dos períodos eleitorais. É notável que, apesar dessas dificuldades, tenha aumentado muito a mobilização dos trabalhadores agrícolas em favor da reforma agrária, forçando o governo a desenvolver o amplo programa de reforma agrária antes mencionado. 
No segundo governo Cardoso, entretanto, o presidente perdeu muito prestígio, principalmente porque o governo não manteve as promessas, desvalorizando a moeda em janeiro de 1999 e desencadeando a desconfiança na sua capacidade de manter a estabilidade monetária. A crise cambial afastou, ao mesmo tempo, a possibilidade de o governo realizar em tempo as promessas de retomada do crescimento econômico. A inflação alta não voltou e as atividades econômicas começaram a crescer, pouco mais de um ano depois, mas, mesmo assim, o presidente não recuperou o prestígio político e a liderança que tinha no seu primeiro mandato. Dessa forma, a coalizão política governamental tornou-se menos disciplinada e o governo perdeu muito de sua capacidade para aprovar leis no Congresso e para definir políticas específicas, dando margem ao fortalecimento dos partidos de oposição. Em contrapartida, tais partidos passaram por grande metamorfose ao longo dos anos, tornando-se cada vez mais permeáveis às idéias liberais. A mudança foi até o ponto de a camada dirigente do principal partido oposicionista, o Partido dos Trabalhadores, não ultrapassar os limites do que temos denominado liberaldesenvolvimentismo.

A luta eleitoral pela Presidência da República, em 2002, exprimiu muito bem as mudanças ocorridas no bloco hegemônico, a debilidade da coalizão política governante e a mudança ideológica dos principais partidos de oposição. Nenhum candidato à Presidência defendeu o fundamentalismo liberal. Além de advogar idéias liberal-desenvolvimentistas, o candidato situacionista não conseguiu manter o apoio de toda a coalizão de sustentação de Cardoso. A ala direita da coalizão abandonou a candidatura oficial mas não teve condições de lançar o seu próprio candidato à Presidência. Foi capaz de mostrar apenas alguma força no plano regional. Por outro lado, os concorrentes de oposição mostraram-se sintonizados com as idéias liberal-desenvolvimentistas, a despeito da exacerbada retórica nacionalista de alguns deles. Especialmente o Partido dos Trabalhadores e seu candidato fizeram grandes esforços para se ajustar ao establishment, seja comprometendo-se a manter o eixo da gestão econômica de
Cardoso seja aproximando-se do centro do espectro partidário. De fato, além do PT se compor com alguns partidos de esquerda, aliou-se ao Partido Liberal e fez de um empresário, senador por este partido, o seu candidato à vice-presidente.

Em suma, nas eleições de 2002, o conjunto das forças políticas tentou posicionar-se na ala esquerda do establishment. Isto significa que todos eles advogavam mais controle do Estado sobre o mercado, mais incentivos estatais para as atividades produtivas e maior proteção do Estado para os mais pobres, mas tudo isso sem quebrar o molde liberal que conforma a coalizão sociopolítica no poder.

Assim, embora a vitória do Partido dos Trabalhadores na eleição para a Presidência presidência da República tenha resultado, evidentemente, em mudança da coalizão política governamental, ela não tende a produzir qualquer ruptura na hegemonia liberal estabelecida anos atrás. Mesmo que haja tensão entre a nova coalizão político-partidária que comanda o Estado e a coalizão sociopolítica que o vem sustentando, o eixo da agenda do novo governo é liberal-desenvolvimentista: seu objetivo não é reconstruir o Estado empresarial, mas reformar o Estado para que possa estimular o desenvolvimento privado e a igualdade social. ${ }^{38}$

É certo que os novos governantes vêm afirmando que suas políticas ortodoxas são apenas "um remédio inevitável mas provisório", a ser utilizado só enquanto a dívida interna e externa e a estagnação econômica internacional continuarem a constranger a capacidade de ação do Estado. Embora o novo governo queira sugerir com isso que há uma diferença qualitativa da política que adota com a do anterior, não se vislumbra no horizonte nenhuma alternativa de gestão macroeconômica que, alterados os atuais constrangimentos, não pudesse ser adotada também pelo governo Cardoso, caso ainda estivesse no poder. O que se pode esperar, sim, é que o governo Lula no futuro expanda e dê uma maior consistência às políticas de desenvolvimento e às políticas sociais empreendidas pelo governo Cardoso. Dada a dependência do Estado em relação ao capital financeiro, não parece provável a adoção de políticas muito drásticas de redistribuição do patrimônio e da renda, ainda que haja muita boa vontade entre 
as elites em relação a programas de combate à miséria e à pobreza. É verdade, também, que o novo governo tem advogado uma maior participação política no desenho e na gestão das políticas estatais, contrariando o estilo tecnocrático de decisão do governo anterior. E que, em função disso, foram criados vários conselhos consultivos - compostos por representantes convidados de organizações sociais e por membros do governo. Embora as promessas de maior participação política tenham tido, sem dúvida, um alto valor político para a eleição do atual presidente, especialmente entre os empresários e a classe média, ainda é muito cedo para avaliar se os mecanismos imaginados para realizá-las produzirão transformações institucionais significativas que aprofundem a ordem democrática vigente.

Seja como for, o extraordinário conjunto de reformas liberalizantes efetuadas nos anos de 1990 definiu o quadro institucional básico que regulará as relações entre o Estado e o mercado e entre o sistema econômico nacional e o capitalismo mundial no começo do século XXI. Esse quadro dificilmente será alterado a médio prazo, pois é a materialização de uma nova perspectiva hegemônica na sociedade. As mudanças ocorridas na gestão econômica inclinaram-na cada vez mais para o liberal-desenvolvimentismo, e é razoável supor que o novo governo de esquerda tenda a reforçar as características centrais dessa inflexão no campo hegemônico liberal. A dependência externa e o Mercosul são os elos mais frágeis da nova forma de integração do país no capitalismo mundial. De um lado, a incapacidade crônica de gerar poupança interna suficiente para sustentar investimentos ameaça o desenvolvimento econômico contínuo do Brasil. De outro, a fraqueza econômica e a política dos países membros do Mercosul no plano mundial e a falta de harmonia entre eles pode complicar a sua consolidação como bloco regional. Ademais, os Estados Unidos pressionam intensamente para subordinar o Mercosul a um processo de integração que compreende toda a América sob sua liderança.

De uma perspectiva mais ampla, foi notável o progresso brasileiro na direção de uma sociedade mais democrática. Há nítidas manifestações de in- tolerância crescente das classes médias e populares diante do comportamento predatório das elites e também cada vez mais exigências de distribuição mais justa da renda. Essas demandas de responsabilidade política e social tendem a consolidar as instituições políticas democráticas e, como a válvula inflacionária - mecanismo de escape típico daquela elite em face das pressões distributivas - está razoavelmente bloqueada, parece provável que paralelamente ao crescimento econômico venha a ocorrer uma maior redução dos índices brasileiros de desigualdade material e cultural.

Nas últimas décadas do século XX, por maiores que tenham sido as mudanças ocorridas, o Brasil não escapou de sua condição periférica. A retomada do crescimento acelerado e a consolidação do Mercosul não serão suficientes para permitir que isso ocorra. Superar essa condição exige a inclusão social e econômica dos mais pobres, que ainda permanecem à margem das conquistas materiais da civilização moderna. Este é o desafio mais difícil e mais necessário para a sociedade brasileira superar neste século XXI.

\section{NOTAS}

1 Sobre o padrão autocrático de dominação na sociedade e no Estado brasileiros consultar Fernandes (1975). Em relação ao Estado desenvolvimentista brasileiro ver Draibe (1985). Marçal Brandão (1997) faz uma análise das dificuldades da população em participar autonomamente da política mesmo durante o período de democracia populista anterior ao regime militar autoritário instalado em 1964.

2 A moratória brasileira do final de 1982 e a assinatura de acordo com o FMI em janeiro de 1983 sinalizam o caráter externo da crise. Isso não significa ausência de desequilíbrio fiscal. Este não dava, porém, especificidade à crise, ao contrário do que tem sublinhado Bresser Pereira (1993). A diferença é importante pois, se o desequilíbrio fiscal não decorresse principalmente do endividamento externo, o Estado teria maior raio de manobra para resolvê-lo de outra forma. Ver Whitehead (1993, pp.1380 e 1382) para uma análise crítica da interpretação de Bresser Pereira. 
3 Tais mudanças de paradigma e nas políticas econômicas foram estudadas por Helleiner (1994, caps. 6 e 7).

4 A reforma partidária de 1979 rompeu o sistema bipartidário, instituído pelo regime autoritário em 1965. O PDS (Partido Social Democrata) tomou o lugar da Arena como representante do regime e os partidos PMDB, PDT, PTB e PT assumiram o lugar do MDB (Movimento Democrático Brasileiro) como oposição política. Na eleição de 1982, o PMDB elegeu nove governadores de estado e o PDT, um.

5 Em relação à liberalização política ver Velasco e Cruz e Martins (1983) e Lamounier (1985).

6 Sobre o processo de democratização política, adoto a perspectiva de Touraine (1995). A democratização política tem sido sustentada por processo mais amplo de democratização da sociedade brasileira, que não será examinado aqui.

7 O ajuste fiscal escolhido foi muito menos drástico do que o realizado pelo México, em situação similar. Para uma visão comparativa, consultar Kaufman (1988).

8 Faço um relato detalhado dessa crise em Sallum Jr. ( 1996, cap. 2).

9 A campanha das "Diretas" ultrapassou em parte os próprios valores básicos que legitimavam o Estado. A partir de então seria insustentável uma hegemonia fundada na restrição à participação política das classes populares.

10 A Aliança Democrática foi constituída pelo PMDB e pela Frente Liberal, dissidência do PDS, que depois converteu-se no Partido da Frente Liberal (PFL). A candidatura de Paulo Maluf foi lançada pelo PDS e apoiada pelo governo militar.

11 O presidente eleito Tancredo Neves não tomou posse em 15 de março de 1985 porque ficou repentinamente doente, morrendo poucas semanas depois. Em seu lugar foi empossado o vice-presidente José Sarney que governou até 15 de março de 1990.

12 A esse respeito, consultar o trabalho de Noronha, Gebrin e Elias Jr. (2003).

13 Durante o governo Sarney, podem ser contadas como tentativa heterodoxas de superar a instabilidade econômica os planos "Cruzado", lançado em fevereiro de 1986, "Bresser", editado em meados de 1987, e "Verão", cuja vigência foi iniciada em janeiro de 1989.

14 Biersteker (1995) trata desse processo de difusão.
15 No segundo turno eleitoral 37\% votaram em Lula, apenas $4 \%$ menos do que no candidato vencedor, Fernando Collor de Mello.

16 Nesta seção reelaboro parte de análises e informações que constam de Sallum Jr. (1999, 2000). O primeiro texto faz parte, com outros artigos, do "Dossiê FHC - $1^{\circ}$ Governo", publicado na revista Tempo Social (Revista de Sociologia da USP). Mais recentemente, Lamounier e Figueiredo (2002) organizaram uma coletânea de trabalhos sobre o governo FHC, redigidos por jornalistas com base em pesquisas acadêmicas. Este trabalho contém análises de ótima qualidade, mas seus resultados não alteram substancialmente a interpretação aqui desenvolvida.

17 As tarifas médias eram 31,6\% em 1989. Foram reduzidas para 30\% em 1990, para 23,3\% em 1991, para 19,2\% em janeiro de 1992, para 15\% em outubro de 1992 até 19,2\% em Julho de 1993.

18 A primeira equipe econômica de Collor foi substituída em maio de 1991. A negociação da dívida externa, durante seu governo, foi analisada com exatidão em Candia Veiga (1993).

19 Collor renunciou em outubro de 1992.

20 Emprego o termo cesarismo em sentido metafórico. Ver em Bobbio et al.(1994) um texto curto, mas rico sobre o assunto.

21 Sobre o Plano Brady, ver Cline (1989). Um texto sintético sobre os novos fluxos de capital e reformas que caracterizaram a passagem doa anos de 1980 para a década de 1990, consultar Naím (1995).

22 O fluxo voluntário de capital externo começou a voltar ao Brasil em 1991. Suas reservas de câmbio atingiram 42 bilhões de dólares na metade de 1994, quando o Plano Real foi lançado.

23 Há um bom estudo sobre as condições políticas e econômicas na época do Plano Real em Sola e Kugelmas (1996).

24 Malloy e Connaghan (1996) e Mettenhein e Malloy (1998) analisaram algumas experiências políticas latino-americanas sob à luz do que Pocock entende por "momento maquiaveliano". Sola e Kugelmas(1996) estudaram a eleição e o Plano Real de Cardoso sob a mesma ótica.

25 Durante o período de Revisão Constitucional as reformas podiam ser aprovadas por maioria simples. 
26 No segundo governo de Fernando Henrique Cardoso foram aprovadas normas estritas de "responsabilidade fiscal" para os governantes e penalidades para os transgressores.

27 Os principais representantes dessa corrente ideológica no governo foram o primeiro presidente do Banco Central, Gustavo Franco, e o Ministro da Fazenda, Pedro Malan. Fora do governo suas principais expressões intelectuais foram os economistas da PUC-Rio de Janeiro.

28 Apesar da retórica política da oposição política, a sobrevalorização do câmbio não se vincula ao ideário neoliberal, que recomenda, ao contrário, um market exchange. A versão brasileira radical de liberalismo adotou a sobrevalorização para forçar as empresas brasileiras a se enquadrarem rapidamente, sob pena de desaparecimento, aos padrões do mercado, isto é, aos níveis internacionais de preços e produtividade. Eis porque denomino fundamentalista esse tipo de liberalismo.

29 Representavam esse ponto de vista, no primeiro governo FHC, principalmente José Serra, ministro do Planejamento, Luiz Carlos Mendonça de Barros, presidente do BNDES, e José Roberto Mendonça de Barros, secretário de Política Econômica. Fora do governo o nome mais relevante era o do deputado federal Delfim Neto, figura importante do regime autoritário, em que ocupou diversos ministérios da área econômica.

30 Em Sallum Jr. (2000) tratei dessas medidas compensatórias. Sobre o conceito de política industrial referido, consultar Mendonça de Barros e Goldenstein (1997).

31 As taxas médias anuais de desemprego evoluíram da seguinte maneira: 4,85\% (de julho de 1994 a junho de 1995); 5,75\% (1995-1996); 5,77\% (19961997); 7,37\% (1997-1998); e 8,32\% (1998-1999).

32 Tomo o conceito de Braga (1997). Além do texto citado podem ser consultadas os trabalhos de Chesnais (1996, 1998) que, embora de forma um pouco diversa, vão na mesma direção.

33 A própria política de estabilização no primeiro governo de FHC contribuiu para dar vantagens às empresas estrangeiras em relação às nacionais.

34 Em 1996 o IDE atingiu apenas US\$ 9,6 bilhões; em 1997 subiu para US\$ 17,9 bilhões e depois para US\$
26,8 bilhões em 1998, e finalmente para US\$ 31,2 bilhões em 1999.

35 O compromisso de produzir superávit primário anual de 3,5\% do PIB (elevado em 2002 para $3,75 \%$ ) implicou uma grande contenção de gastos. Ainda mais que os números foram de fato superados. Sublinhe-se que, durante o primeiro mandato de FHC, embora o governo defendesse a necessidade de ajustar as contas públicas, apenas as manteve equilibradas (não contando os juros pagos).

36 Os fluxos de IDE foram de US\$ 33,3 bilhões em 2000, caíram para US\$ 20 bilhões em 2001 e para US\$ 16,6 bilhões em 2002. As dificuldades de rolagem da dívida interna manifestaram-se apenas em termos de custo monetário mais alto. Em relação à dívida externa, houve redução dos montantes disponíveis para renovar linhas de crédito às exportações, algo que não ocorrera sequer na crise dos anos de 1980.

37 Apesar do considerável ajuste fiscal, o Brasil não conseguiu reduzir a proporção de sua dívida pública em relação ao PIB. Em compensação, a enorme desvalorização cambial relacionada à incerteza eleitoral de 2002 ajudou o Brasil a gerar um superávit comercial de US\$ 13,1 bilhões, o que reduziu o déficit externo corrente a 1,7\% do PIB (entre 1998 e 2001 o déficit anual tinha atingido mais de $4 \%$ do PIB).

38 É importante sublinhar que no Brasil e em outros países latino-americanos os adeptos do liberalismo econômico não costumam se opor ao Estado de Bem-Estar, mas ao Estado Empresário (nacional-desenvolvimentista), manifestando-se a favor de políticas sociais.

\section{BIBLIOGRAFIA}

BRAGA, José Carlos de Souza. (1987), "Financeirização global: o padrão sistêmico de riqueza do capitalismo contemporâneo", in Maria da Conceição Tavares e José Luís Fiori (orgs.), Poder e Dinheiro: uma economia politica da globalização, Petrópolis, Vozes.

BOBBIO, Norberto et al. (1994), Dicionário de politica, 6 ed., Brasília, Editora da UnB, vol. 1. 
CHESNAIS, François. (1996), A mundialização do capital. São Paulo, Xamã.

(org.). (1998), A mundialização financeira: gênese, custos e riscos. São Paulo, Xamã.

CLINE, William. (1989), "From the Baker plan to the Brady plan", in Israt Husain e Ishac Diwan (eds.), Dealing with the debt crisis, Washington D.C., World Bank Simposium.

BIERSTEKER, Thomas. (1995), "The "triumph" of liberal economic ideas", in Barbara Stallings (ed.), Global change, regional response, Cambridge, Cambridge University Press.

BRESSER Pereira, Luiz Carlos. (1993), "Economic reforms and cycles of State intervention". World Development, 21 (8).

CANDIA VEIGA, João Paulo. (1993), Dívida externa e o contexto internacional. Dissertação de mestrado apresentada no Departamento de Ciência Política, São Paulo, USP.

DRAIBE, Sonia. (1985), Rumos e metamorfoses: Estado e industrialização no Brasil, 1930-1960. Rio de Janeiro, Paz e Terra.

EDWARDS, Sebastian. (1995), Crisis and reform in Latin America: from despair to bope. Nova York, World Bank/Oxford University Press.

FERNANDES, Florestan. (1975), A revolução burguesa no Brasil. Rio de Janeiro, Zahar Editores.

HELLEINER, Eric. (1994), States and the reemergence of global finance. Ithaca/Londres, Cornell University Press.

KAUFMAN, Robert. (1988), The politics of debt in Argentina, Brazil, and Mexico: economic stabilization in the 1980s. Berkeley, IIS-University of California.

LAMOUNIER, Bolivar. (1985), "Apontamentos sobre a questão democrática brasileira”, in Alain Rouquier, Bolivar Lamounier e Jorge Schvarzer (orgs.), Como renascem as democracias, São Paulo, Brasiliense.
LAMOUNIER, Bolivar \& Figueiredo, Rubens (orgs.). (2002), A era FHC: um balanço. São Paulo, Cultura Editores Associados.

MALLOY, James \& CONNAGHAN, C. (1996), Unsettling Statecraft, democracy and neoliberalism in Central Andes. Pittsburg, Pittsburg University Press.

MARÇAL BRANDÃO, Gildo. (1987), A esquerda positiva. São Paulo, Hucitec.

POCOCK, John. G. A. (1975), The machiavelian moment. Princeton, Princeton University Press.

MATTENHEIM, Kurt \& MALLOY, James. (1998), "Introduction", in K. Mattenheim e J. Malloy (eds.), Deepening democracy in Latin America, Pittsburgh, University of Pittsburgh Press.

MENDONÇA DE BARROS, José. Roberto. \& GOLDESTEIN, Lídia. (1997), "Prefácio", in BNDES, Balança comercial brasileira, Rio de Janeiro (série "BNDES Setorial", edição especial).

NAÍM, Moises. (1995), "Latin America the morning after". Foreign Affairs, 74 (4), jun.-ago.

NORONHA, Eduardo G.; GERIN, Vera \& ELIAS JR., Jorge. (2003), "Explaning an exceptional wave of strikes: from authoritarian Brazil to democracy". Artigo com aceitação preliminar para publicação no British Journal of Industrial Relations, Oxford, Blackwell Publishers.

SALLUM JR., Brasilio. (1996), Labirintos: dos generais à Nova República. São Paulo, Hucitec/Sociologia-USP.

. (1999), "O Brasil sob Cardoso: neoliberalismo e desenvolvimentismo". Tempo Social (Revista de Sociologia da USP), São Paulo, 11 (2): 23-47, out.

(2000), "Globalização e desenvolvimento: a estratégia brasileira nos anos 90". Novos Estudos Cebrap, 58, nov.

SOLA, L. \& KUGELMAS. (1996), "Statecraft, instabilidade economica e incerteza política: o Brasil em perspectiva comparada”, in Eli Diniz (org.), Anais do seminário in- 
ternacional: o desafio da democracia na América Latina, Rio de Janeiro, Iuperj, pp. 398-414.

TOURAINE, Alain. (1995), "Democracy: from a politics of citizenship to a politics of recognition", in Louis Maheu (ed.), Social movements and social classes: the future of colletive action, Londres, Sage/ISA.

VELASCO E CRUZ, Sebastião \& MARTINS, Carlos E. (1983), "De Castello a Figueiredo: uma incursão na pré-história da 'abertura", in Bernardo Sorj e Maria H. Tavares, Sociedade e política no Brasil pós64, São Paulo, Brasiliense.

WHITEHEAD, Laurence. (1993), "On 'reform of the State' and 'regulation of the market'". World Development, 21 (8): 1371-1393. 


\section{METAMORFOSES DO ESTADO BRASILEIRO NO FINAL DO SÉCULO XX}

Brasilio Sallum Jr.

Palavras-chave

Estado; Desenvolvimentismo; Democratização; Liberalização econômica; Transição política; Brasil.

$\mathrm{O}$ artigo procura reconstruir o processo de crise do Estado varguista e de transição para a forma nova forma de Estado, moderadamente liberal em termos econômicos e democrática em termos políticos, que emergiu nos anos de 1990, ganhou solidez durante sob a presidência de Fernando Henrique Cardoso e foi reiterada com a eleição de Luiz Inácio da Silva. Procura-se explorar a natureza da crise de hegemonia que marcou o início da transição política brasileira, no início dos anos de 1980, e caracterizar a emergência de um novo padrão hegemônico de dominação. Ressalta-se principalmente os dois aspectos principais da transição política - a democratização política e a liberalização econômica - procurando-se salientar as transformações da sociedade nacional e da ordem mundial em que se inserem.

\section{METAMORPHOSIS OF THE BRAZILIAN STATE IN THE END OF THE TWENTIETH CENTURY}

Brasilio Sallum Jr.

\section{Key words}

State; Development; Democratization; Economic liberalization; Political transition; Brazil.

The article aims at reconstructing both the process of crisis of the State during the Vargas era and the transition process towards a new format of State, which was moderately liberal in terms of economy and democratic in terms of politics, that emerged in the nineties, became consolidated during the presidency of Fernando Henrique Cardoso, and has been reiterated with the election of Luiz Inacio Lula da Silva. It also explores the nature of the hegemony crisis found in the beginning of the Brazilian political transition in the early eighties, as well as characterizes the appearance of a new hegemonic standard of domination. It calls attention for two main aspects of the so-called political transition - the political democratization and the economic liberalization - as it enhances the transformations of both the national society and the world order in which they are inserted.

\section{MÉTAMORPHOSES DE L'ÉTAT BRÉSILIEN À LA FIN DU XX SIÈCLE}

Brasilio Sallum Jr.

\section{Mots-clés}

État; Processus de développement; Démocratisation; Libéralisation économique; Brésil.

Cet article propose une reconstruction de la crise de l'État sous l'ère Vargas ainsi que du processus de transition vers une nouvelle forme d'État, modérément libéral en termes économiques, et démocratique du point de vue politique. Cette nouvelle forme d'État apparue dans les années 1990, s'est consolidée sous le gouvernement de Fernando Henrique Cardoso et a été réaffirmée suite à l'élection de Luiz Inácio Lula da Silva. Nous explorons la nature de la crise d'hégémonie qui marqua le début de la transition politique brésilienne au début des années 80 et tentons de caractériser l'émergence d'une nouvelle référence hégémonique de domination dans les années suivantes. Nous nous sommes attachés, particulièrement, à deux aspects principaux de la transition - la démocratisation politique et la libéralisation économique -, en mettant l'accent sur les transformations de la société nationale et sur l'ordre mondial dans laquelle elle s'inscrit. 